\title{
Trampas naturales en "La isla en peso" de Virgilio Piñera. Hacia una narrativa de la persecución de la historia-histeria cubana ${ }^{1}$
}

\author{
Félix Miguel Rosario Ortiz ${ }^{2}$ \\ Cornell University (Estados Unidos) \\ ORCID ID: 0000-0002-8806-5284
}

Recibido: 20 de marzo de 2019

Aceptado: 9 de mayo de 2019

\begin{abstract}
RESUMEN
Como respuesta a los imaginarios insulares previamente esbozados por escritores de la literatura cubana del siglo XX, Virgilio Piñera concibe un hablante lírico a quien le es asignada la tarea de precisar la historia mítica de un país llamado Cuba. Apostando por un lenguaje económico, y por momentos antipoético, en "La isla en peso" se describe una ciudad que es posible por la infatigable presencia de la luz. Sin embargo, esta ubicuidad luminosa, aunque permite atestiguar las actividades de la ciudad habanera, se acaba transformando en un elemento persecutorio que, auxiliado por el mar y el entretenimiento, conforman una suerte de "historia-histeria". Ante tal escenario, esta voz lírica, movida por un impulso mesiánico, hace hincapié en una serie de elementos que, a su juicio, han propiciado la inestabilidad del lugar representado. Se trata, pues, de un entorno en donde el hábitat opresor domina el hábito carnavalesco y, a su vez, en donde el hábito reconoce al hábitat por sus trampas naturales.
\end{abstract}

Palabras clave: persecución, vigilancia, insularidad, "La isla en peso", Virgilio Piñera

\begin{abstract}
In response to the insular imaginaries previously outlined by writers of the twentieth century, Virgilio Piñera conceives a poetic voice that is assigned with the task of drawing the mythical history of a country called Cuba. Using a transparent and, at times, antipoetic language, in "La isla en peso" this lyric voice describes a city that is possible because of the relentless presence of light. However, this luminous ubiquity, although it does allow the witnessing of the activities embedded in daily life, ends up becoming a persecutory element that, along with the presence of the sea and entertainment, forms some kind of "history-hysteria". Given that scenario, the lyric voice, moved by a messianic impulse, aims at a series of elements that, in his opinion, have led to the instability of the represented place. It is, then, an environment where the oppressive habitat dominates the extravagant habit, and, at the same time, where the habit recognizes the habitat for its natural traps.
\end{abstract}

Keywords: persecution, surveillance, insularity, "La isla en peso", Virgilio Piñera

\footnotetext{
${ }^{1}$ Natural Traps in "La isla en peso" by Virgilio Piñera: Towards a narrative of the persecution of Cuban history-hysteria

${ }^{2}$ Estudiante del doctorado de Estudios Romances en Cornell University, Estados Unidos. Correo electrónico: fmr34@cornell.edu
} 


\section{I.}

Si se hiciera una revisión genealógica apresurada en torno a las narrativas de la persecución sería posible percibir contenidos latentes desde las manifestaciones homéricas sobre su Ulises heroico. El perseguido, indistintamente de épocas, países y generaciones literarias, ha poblado todas las tradiciones. Raskolnikov erige un laberinto para sí en el que la tormenta está fijada a la memoria del acto criminal cometido. Josef K. carga una condena inefable que lo llevará, irremediablemente, a la muerte. Mersault, incluso frente a su crimen, no podrá escapar de la indiferencia que le suscita su existencia.

Fuera de la literatura, compete señalar que el siglo XX se encargó de insistir en las narrativas de la persecución por acontecimientos tales como las guerras mundiales, el nazismo, la bomba atómica, la guerra fría y el enfrentamiento tácito del comunismo y el capitalismo, el crecimiento de los medios de comunicación, el desarrollo de la tecnología, el terrorismo, entre otros acontecimientos. Sin duda, este conjunto de fuerzas está destinado a impactar el imaginario ciudadano haciendo difusa la distinción entre irracionalidad y racionalidad. Como consecuencia, los modelos de pensamiento están siendo constantemente reconstruidos. Más allá de resignificar el evento y de entender la naturaleza de este, la consecución irrefrenable del caos imposibilita el estudio detenido del accidente como hecho ético y estético, es decir, la revisión minuciosa y desapasionada del acontecer lineal.

A la imposibilidad de revisión detallada, se suma la celeridad, no de eventos, sino de constancia de eventos: cualquier suceso de la cotidianidad podría agarrar tracción hasta conseguir categoría de "viralidad". Esta noción epidémica se define en la colectividad como un agente externo que trasciende las interpretaciones tradicionales de la paranoia. En este punto no se trata de la perturbación en estado de delirio (y martirio), que se asocia fácilmente a esta condición como un padecimiento mental. En Paranoia: The Madness that Makes History, Luigi Zoja establece que "with the ending of the twentieth century and the dawn of the twenty-first, paranoia has escaped from clinical discourse and is rarely pointed out as a danger because it has pervasively infiltrated everyday speech. In an unconscious and indirect way, it has corrupted many ideas of politics and justice" (2017: 275). Ante esta proliferación de información, de miedos y, finalmente, de incertidumbres, se crea el pensamiento engañoso o el razonamiento paranoico.

En la actualidad, todo es alcanzable por la luz, todo está a segundos de una captura, a segundos de ser difundido, extendido, extenuado. Todo lleva a cierta abolición de la secretividad. La producción del caos no entiende de fatigas, y prescinde de autor y autoridad; vale más la información que el filtro. En ese sentido, según Zoja "paranoia is disguised as life -in its seeming normality, the way it merges with everyday life- but it is not life [...] It puts on an act, the better to strike anyone who lowers their guard" (2017: 266). Dicha asunción de espectacularización y especulación deviene en proceder paranoico por un grupo que es capaz, casi inconscientemente, de suprimir sus creencias morales por lo que estima un bien mayor o, peor aún, que su sentido de justicia le hace creer incapaz de llevar a cabo cualquier acto cifrado de maldad. Sobre esta normalización, Zoja indica 
nuevamente que: "individual paranoia often originates from a just passion (or from a passion of justice) [...] mass paranoia is a question not of passions but of enthusiasms. Real passion is capable of long-term planning and great self-discipline [but all you need is] enthusiasm, [a] moment of strong positive adherence to something that seems a vision of future" (2017: 282-3). A fin de cuentas, esta acumulación del miedo alcanza a ser la expresión de la experiencia del sujeto moderno, dada la aparente persecución ininterrumpida que resulta en deformación a diferentes niveles, con lo que se pone en pugna el valor didáctico del sufrimiento y el mesianismo, en ocasiones accidental, que se otorga el sujeto privado que participa en estos encuadres de narración y complot.

Los representantes de la cultura en Cuba, igual de condenados a las inquietudes originarias del individuo de todos los tiempos, se han entreverado en dicha tradición. Cabe destacar que el interés de esta investigación no es convertirse en un museo de la persecución estatal -para eso sería más prudente un acercamiento estrictamente histórico. Lo que se procura definir es la naturaleza de la angustia existencial tomando en cuenta la situación de Virgilio Piñera y entendiéndola desde la no-pertenencia y el desarraigo, dada la etiqueta de exiliado total que parece asignársele. En ese sentido, se hará hincapié en las instancias poéticas en las que la voz de "La isla en peso" se reafirma con tal de determinar sus intentos de inserción histórica. Asimismo, se destacará la actitud irreverente de Piñera que, más que mero acto provocador, refleja una formación poética tremendamente incomprendida.

Piñera, alejándose de los preceptos desarrollados por el neobarroco, se inclina por un lenguaje comunicativo por encima del decorativo, tan favorecido por otros escritores tales como Alejo Carpentier, Severo Sarduy, José Lezama Lima, Cintio Vitier, Eliseo Diego, entre otros. Según Stephen A. Cruikshank: "Piñera's objective of writing La isla en peso can be considered as a deconstructive project that aimed to undo the discourse of cultural nationalism addressed by the Orígenes group. He [...] wrote 'illiterately' against the post-colonial assertions of national culture being condoned by the majority of his neobaroque contemporaries" (2016: 20).

No hay que olvidar, en este sentido, el quehacer cultural de Cuba de la primera mitad del siglo XX ni las inquietudes de los artistas de entonces. Tal como establece Jeisil Aguilar Santos, la característica esencial de esta generación es "la recurrencia a la ausencia de la nación y la búsqueda de un ideal que rebasa la corrupción ética y a la vez cultural de esta etapa de la República cubana" (2015: 47). Durante este período, que comprende de 1939 a 1961, los intelectuales se enfrascaron en la publicación de revistas de las que destacan Espuela de Plata, Nadie Parecía, Orígenes, Ciclón y Lunes de Revolución, por lo que se funda "una nación desde la poesía" (Aguilar Santos, 2015: 47). Bajo esa aspiración de cambio radical, de búsqueda de identidad nacional y de fundación de una nueva sociedad por medio del arte, Virgilio Piñera se asoma a su ambiente literario.

Si bien sus primeros poemas aparecen en Espuela de Plata (1939-1941), ${ }^{3}$ Las furias (1941) y otra revista creada por él mismo, Poeta (1942), es con "La isla en peso" (1942) que Piñera parece

\footnotetext{
${ }^{3}$ Espuela de Plata es una de las revistas predecesoras de Orígenes. Fue fundada por José Lezama Lima, Guy Pérez Cisneros y Mariano Rodríguez.
} 
alcanzar cierta madurez poética. Con este texto, el autor se hace valer de recursos antipoéticos para romper con los cánones de la lírica más tradicional. Igualmente, las acentuaciones absurdas, que chocan notablemente con todas las visiones de insularidad propuestas por otros de sus contemporáneos, resaltan por la mordacidad y la socarronería con la que enuncia. Este modo de expresión muy suyo le hizo ganar lectores disconformes, entre los que vale mencionar a Gastón Baquero y Cintio Vitier. Para Baquero

Es como si el poeta no considerase que no reconocemos nuestros elementos vivos, nuestra plática viviente, y por no reconocerle desviamos las aproximaciones a su rica intimidad [...] Esta Isla que Virgilio Piñera ha levantado en el marco de unos versos inteligentes, audaces, a veces deliberadamente llamativos y escabrosos, en desconexión absoluta con el tono cubano de expresión, es Isla de una antillanía y una martiniquería que no nos expresan, que no nos pertenecen. [...] viene a aportarnos una de las tendencias extremistas, negativistas, deformadoras intencionadas de nuestra realidad (Baquero, 1944: 307-309).

Mientras que para Vitier: "[E]sa ocasional ternura [en "La isla en peso"] parece como que debilita y extravía su visión, ya que ésta en rigor no se refiere a un estado susceptible de penetrar en ninguna intimidad, en ningún movimiento de compasión o inteligencia, sino al extraño hueco sin fin que nos ataca" (Vitier, 1948: 80), y se refiere a su "Retórica, pulpa, abundancia podrida, lepra del ser, caos sin virginidad, espantosa existencia sin esencia” (Vitier, 1970: 480). De este modo, pese a su éxito previo como dramaturgo, es sólo a partir de su libro Poesía y prosa (1944) que Piñera consigue convencer a sus pares descreídos, al punto de que el propio Vitier le dedicará un comentario celebratorio en la revista Orígenes.

En el caso que me concierne, se verá cómo el escritor apuesta por refuncionalizar el lenguaje, insistiendo en la desnudez de la palabra y la simplicidad expresiva o, en palabras del mismo sujeto lírico en "[u]na poesía exclusivamente de la boca como la saliva" (Piñera, 1969: 39). Por otra parte, la voz poética, en su misión iluminadora, concentrará sus esfuerzos descriptivos en la noche, convencida la voz de que es justamente en ese momento donde todo ocurre, donde se puede escapar de la constante vigilancia, donde se abre y se cierran los secretos, en donde se concilia uno con lo animal. Interesa, entonces, la atribución de la noche como refugio en contraposición a la caracterización lumínica como señal evidente del acoso. El propósito de este trabajo consiste entonces en determinar cómo el hábitat opresor domina el hábito carnavalesco, hasta confundir la negación del ocio con el ocio mismo. En ese mismo sentido, se procura demostrar cómo el hábito reconoce en su hábitat todas las trampas naturales que conforman esa "historia-histeria" cubana de la que el sujeto lírico da constancia.

\section{Piñera: habitante mítico de la metacárcel}

En el caso de Virgilio Piñera, cualquier señal de angustia sostenida y de ensimismamiento responderá al hecho de haber sido víctima del ostracismo tanto bajo el régimen de Fulgencio Batista como del de Fidel Castro. Al haber sido perjudicado por la censura se le prohibió publicar dentro y fuera del país. A ese respecto, apunta Rita Molinero que: “[...] a pesar de su aparente 
fragilidad y del miedo tan presente en Piñera y en los protagonistas de su narrativa, se enfrentó con valentía [...] a todos los extremos que han definido el canon literario cubano a través de su historia: indiferencia, rechazo, incomprensión, olvido, sorpresa, asombro" (2012: 29). A raíz de su producción de literatura de urgencia -una escritura por momentos tosca, con pasajes de tal autenticidad que dan la impresión de ser autobiográficos por su contundencia-, Piñera contuvo el temor y la rabia alojándola dosificadamente por toda su obra. Molinero insiste en las condiciones con las que el escritor cubano se enfrentó -esa suerte de "muerte civil"-, enfatizando en que "Piñera conoció asimismo la infamia de la roña, ese tipo de malignidad cubana, prima hermana de la envidia, que propicia la proliferación de perseguidores y perseguidos" (2012: 31). Es, bajo esa atmósfera, que consigue escribir uno de sus poemas más celebrados.

La multiplicación de instancias poéticas en este texto parece evocar una inestabilidad. El lector flota en torno a la isla que el alquimista evoca. Este recurso polifónico se antoja un ejercicio de exhibición de claroscuros, en el que la luz permite la belleza, pero también exhibe los signos de monstruosidad del entorno, además de que habilita el acoso. Rita Martin indica que

[...] para Virgilio el sujeto contemporáneo no expresa su pensamiento sino que repite un lenguaje acumulado, establecido y oficial, en el cual no ha intervenido el agente activo de la imaginación del individuo. La no intervención del sujeto en la construcción de la palabra muestra la relación ajena que este sostiene con el mundo que le rodea, lo cual provoca las evidencias de esta muerte a través de los signos de la incomunicación y la enajenación (2009: 46).

Piñera, con gran maestría, utiliza un código lingüístico que no responde ni al lenguaje de la superabundancia ni al lenguaje meramente explicativo. De ese modo, eleva a discurso literario un texto que no puede ser decodificado por el sujeto contemporáneo -carente de perfil imaginativo, según Martin-, pero que habla por este sujeto. El mundo que le rodea es un mundo, curiosamente, ajeno a sí, pero trata de desmenuzarlo, de articularlo. Con ánimo de perseguir estas ideas, procuro circunvalar el poema antes mencionado. De entrada, gran parte de los versos de la primera estrofa demuestran una contención de orden aparentemente represivo o, al menos, tortuoso. La voz lírica irrumpe con:

La maldita circunstancia del agua por todas partes

me obliga a sentarme en la mesa del café.

Si no pensara que el agua me rodea como un cáncer

hubiera podido dormir a pierna suelta.

Mientras los muchachos se despojaban de sus ropas para nadar

doce personas morían en un cuarto por compresión.

Cuando a la madrugada la pordiosera resbala en el agua

en el preciso momento en que se lava uno de sus pezones,

me acostumbro al hedor del puerto, 
Una taza de café no puede alejar mi idea fija,

en otro tiempo yo vivía adánicamente (Piñera, 1969: 25).

Como se puede apreciar, la voz hablante pasea su lirismo ejercitando el alcance visual y la intelección acompañada de la memoria. De ese modo, elabora una angustia tangible; ni el miedo ni la paranoia han distorsionado enteramente sus mecanismos de comprensión, por lo que la entelequia poética aún se limita a la interacción empírica. A partir de los primeros dos versos, el Yo lírico ejecuta un acto cartográfico con el que define y marca los distanciamientos. Ni el circuito marítimo de la isla ni la circularidad de la taza representan la perfección, más bien presentan el sitio, la trampa que se habita. Para el crítico Juan Carlos Quintero-Herencia: “[...] ante la mar [...] poéticas matrices ejercitan devenires del espacio, ensamblan lugares, articulan dondes [...] para el cuestionamiento, pero también estas poéticas construyen lugares de indistinción entre el espacio y el sujeto que los habita. Si se quiere, a la costa el sujeto poético va a dudar de su unicidad, a complicar y complejizar su supuesta relación armónica con su entorno cultural (2012: 78). El individuo atormentado está atrapado dentro del límite natural que lo obliga a reproducir acciones pasivas. Esa prisión húmeda priva al poeta de experimentar el mundo mediante la comunión sensorial, de ejercer su dinamismo de flâneur acuático, por lo que está condenado al rol de observador, de voyerista. ${ }^{4}$

Pensando en la alegoría platónica de la línea, a la voz hablante, representante lírico de Piñera, la condición insular le impone la contemplación como única vía para la consecución artística. Según Quintero-Herencia, en este texto “[...] la detención subjetiva del isleño se nombra como varamiento, como una imposición de las aguas del litoral a la capacidad de movimiento del poeta [...] la política-poética piñeriana es un asunto perceptivo que se desata en el litoral" (77-78). Pero aquí no hay caverna ni ascenso lógico ni descenso sensible, aquí todo es agua y luz, y posibilidades caóticas que engullen lo imperfecto y lo ideal, lo paradisíaco y lo infernal. En el tercer y cuarto verso se afianza la sensación de tormenta -hasta de hipocondría- que impide conciliar "el sueño de los peces" (Piñera, 1969: 25). Nuevamente, el caos impera, puesto que no se pueden establecer puentes más allá del margen: "me acostumbro al hedor del puerto" (1969: 25).

Asimismo, el agua no es simple y observablemente amenazadora, sino que entraña y asume su ir caótico, su violencia oleada. Por un lado, acepta a los cuerpos penetrantes y aparentemente jóvenes que nadan en ella, pero también funge su papel de trampa y, en medio de un acondicionamiento rutinario, provoca el desliz, la caída frustrada. Frente a todo esto, el espectador protagónico es incapaz de engañarse ni de paliar con su bebida abrasadora el hecho de saberse habitante mítico de la metacárcel. Esta angustia, sin embargo, no se intenta saciar con tragos de indiferencia, al contrario, es maximizada, pues la voz poética recurre a la memoria, a un Yo primitivo, que evoca la libertad adánica que alguna vez le perteneció. Del mismo modo, con esa alusión al Yo primitivo

${ }^{4}$ Esta denominación no es del todo descabellada. Para validarla, que no es el objeto de estudio en este momento, habría que contrastarla pormenorizadamente con el poético "whale-road", famoso circunloquio (de asociación por contigüidad) en Beowulf. 
que "vivía adánicamente” seguido del “¿qué trajo la metamorfosis?” (Piñera, 1969: 25), se procura, en tan solo la primera estrofa, ir desmontando la noción de la isla tropical como un destino paradisíaco.

El poema, como se puede apreciar en la segunda estrofa, continúa fijando sus pilares en la cuestión del mar problemático

La eterna miseria que es el acto de recordar.

Si tú pudieras formar de nuevo aquellas combinaciones,

devolviéndome el país sin el agua,

me la bebería toda para escupir al cielo,

Aún flota en los arrecifes el uniforme del marinero ahogado.

Esta noche he llorado al conocer a una anciana

que ha vivido ciento ocho años rodeada de agua por todas partes. (Piñera, 1969: 25-26)

Una vez más, el ejercicio de la memoria encabeza toda una enumeración sobre las consecuencias que acarrea el mar -y la levedad histórica que esto parece dejar-; se trata de una cabeza flotante, que poetiza a relieve, corriéndose el riesgo de morir ahogada. El acto de recordación es terrible, pero necesario, y el hablante lírico lo sabe. Por eso se dirige a un "Tú" desconocido, a un "Tú" al que se incita con tal de que este pueda sumarse a la actividad combinatoria que provee la voz al tratar de dar las primeras señales del país. A juicio de Quintero-Herencia, “[...] el sujeto piñeriano busca sortear [...] una condición segregada por el cerco de una mismidad tropical sobre la cultura de la isla. Es la misma agua la que [...] ha hecho indistinguibles un objeto del otro" (2012: 80). Esta indistinción a la que alude el crítico cobra relevancia con el verso final de la primera estrofa, pues engloba la pérdida por partida doble: por un lado, la idea fija sobre la vida adánica -léase: perfecta- y por otro la afasia o la impotencia de nominar las cosas. Todo se trata no tan sólo de una persecución que sufre el cuerpo lírico, sino de una persecución que realiza este por sobre su mítica colonia originaria.

Este poema es una imploración secular. La voz poética (el Yo) está en la búsqueda de las claves para la redención con tal de convencer al "Tú" perdido -el viejo sistema operario del tu-yo, que jerarquiza la posesión en el otro-capaz de "formar de nuevo aquellas combinaciones", o sea, de reinstaurar el tiempo en el que el agua no era repetición. Según María de las Nieves Hernández “[...] aquí el yo poético simula desdoblarse, hablar con el poeta que él mismo es, y pedirle -sabiéndolo imposible- que a través de la poesía le devuelva un país otro, del que solo tiene el recuerdo" (2013: 42). Se trata de un Yo que interroga y amenaza, pero que es consciente de las fuerzas míticas que posee el Tú escindido. El impulso de escupir el agua al cielo no es un intento de deificación, sino 
más bien de deicidio o, al menos, de "metaencarcelar" al Tú puesto en posición ventajosa.

Por otro lado, el uniforme del marinero ahogado demuestra que el flâneur acuático es inútil. En ese sentido, Quintero-Herencia hace hincapié en que "El trópico aparece, entonces, como una invasión perceptiva que desautoriza cualquier ordenanza hermenéutica de sus elementos. Se trata [...] de una paisajística dañada por el derramamiento universal del agua que, por su parte, no otorga ninguna superioridad o serenidad nominativa al sujeto que la contempla" (2012: 81). El mar, entonces, representa la sustancia de estancia y vigilancia a un mismo tiempo. Asimismo, la metacárcel es compartida con habitantes más antiguos, Evas incapaces de convertirse en aves para la huida, Evas que resbalan al lavar su cuerpo con el líquido maldito o que viven condenas centenarias. Por ello, "[...] el cerco de las aguas hace a la isla y a la vez este acoso condiciona los hábitos del cuerpo cultural de sus moradores. Ahí residen los horrores, la risa y el gozo de los cuerpos compartidos en lo insular que el poema entrega" (80).

En la tercera estrofa el poeta exhibe cierto grado de mesianismo que condensa en los versos: "El baile y la isla rodeada por todas partes / [... / ¡País mío, tan joven, no sabes definir!” (Piñera, 1969: 27). En estas líneas es posible notar que los circuitos de delimitación líquida son contraatacados por el pueblo con manifestaciones extendidas del espectáculo. Para Hernández: "[...] la diferencia primordial entre el sujeto lírico y los otros (el pueblo) estriba en que el primero conoce la enajenación del segundo y llega a escribirla. La vida del hablante poemático es la agonía que supone la muerte cotidiana que viven los otros" (2013: 40). Es decir que el sujeto lírico es poseedor -mediante mecanismos propios de megalomanía- de una verdad poética que no fecunda en la credulidad popular. Este ha asumido un mesianismo privado por reconocerse superviviente y observador de la adversidad.

Es decir, que la proyección psicológica en la otredad implica, de algún modo, una empatía distorsionada. Se trata, como se viene insinuando, de una escisión del Yo que enriquece al individuo primo, pero que continúa en un dinamismo de futilidad, pues el intento de transferencia del hecho estético no surte efecto sobre la otredad empobrecida por la ignorancia y espectáculo: “¿Quién puede reír sobre esta roca fúnebre de los sacrificios de gallos?” (Piñera, 1969: 27). En ese sentido, el Yo retuerce los límites de la soledad en su beneficio, pues puebla su marginación con una figura similar -en condiciones-, pero ignorante de la verdad. Hernández respalda esta perspectiva sentenciando que "[...] la consistencia del yo descansa en la racionalidad y en la poesía. El mundo, por su parte, representa el exterminio de ambos dones y, a la vez, una seducción ponderosa e irresistible: la sensualidad y el disfrute sexual" (2013: 40-41). El sujeto lírico es dominado por un afán múltiple -estético, fáustico y de medro-; pretende, por la fuerza de su canto, erigir en torno suyo un museo del caos. Pero, ¿cómo se mete una cultura viva en un recinto?

Cabe destacar que el agua no es el único sistema opresivo en este espacio dado al desorden. La luz también opera como panóptico natural que, por su intensidad, destroza el alcance visual. Dos versos recogen esta idea: "No puedo mirar con estos ojos dilatados. / Nadie sabe mirar, contemplar [...]" (Piñera, 1969: 30). Con esta represión ocular ocurre una disminución del ente racional por 
uno de orden animal. Nuevamente, Hernández considera que

A diferencia de los casos anteriores, el yo y el otro, que siempre es nadie, se homologan, no en virtud del cumplimiento de la voluntad de acceso a la exploración sensual del mundo. Todo lo contrario. En la lógica del sujeto singular, la visualidad lo constituye ser racional; ese ámbito no pertenece al registro propiamente sensitivo porque, mientras este obstruye el pensamiento, aquella es considerada su condición previa y necesaria. La mirada es el instrumento que le permite conformar un mundo-objeto (lo otro), y al mismo tiempo corroborar los juicios sobre él con un criterio de certeza. Perderla es igual a recobrar los otros sentidos. Es comprensible, por tanto, que en esta vuelta a su disyunción constitutiva, se queje de la incapacidad súbita para mirar (no puedo) y estime sustancial la de otros (no saben) (2013: 44).

En apariencia, aquí hay un enfrentamiento entre las dos escisiones del Yo: el sujeto atávico -el ser adánico, habitante edénico de sentidos predominantemente animales como el olfato- contra el sujeto moderno -óculo-centrista, poseedor de la verdad. No debe olvidar el lector que este poema presenta otras personas gramaticales "[...] para enmascarar el punto de vista y representar [...] los movimientos que ensaya el yo en su intento dramático de realizarse en la multiplicidad del otro" (Hernández, 2013: 40). Las instancias poéticas operan como agentes del orden ante el terrorismo doméstico del Yo en la metacárcel insular. Y es que, al decir de Quintero-Herencia, "la ofuscación es la mejor condición emotiva de ese cuerpo de imágenes que cae entre la manía desesperada y la ceguera. El sujeto isleño y su geografía, en Piñera, están atrapados” (2012: 82).

Estos invasores ejemplifican la batalla interna de la duda, la autopersecución y la tormenta a la que se somete el sujeto lírico por ser el portador de una verdad reveladora y aplastante. Lo sorprendente es que, por momentos, parecería escapárseles a estos ejecutantes de la norma la disposición de desafiliarse de la autoridad si atestiguaran la revelación detentada por ese Yo al que procuran suprimir a base de miedo y dosis de espectáculo: "Es la confusión, es el terror, es la abundancia" (Piñera, 1969: 29). Atormentado por la persecución y las torturas a las que implícitamente es sometido, vuelve la conciencia del encerramiento. La estrofa sigue así:

El horroroso paseo circular,

el tenebroso juego de los pies sobre la arena circular,

los siniestros manglares, como un cinturón canceroso,

dan la vuelta a la isla,

los manglares y la fétida arena

aprietan los riñones de los moradores de la isla (Piñera, 1969: 32).

En este pasaje se describen las fronteras que atentan contra la huella y provocan la enfermedad. El acto del pie consiste en duplicar, como en una recreación microcósmica, los límites mínimos pero ubicuos que cercan al cuerpo durante el paseo. Este hacinamiento potencia el decaimiento general, 
por lo que

salir a la Naturaleza Insular es topar con esta contrariada somatización líquida de un mapa y una temporalidad cotidianas que trastorna y confunde cualquier genealogía. El acoso de lo acuático es la alteración ineludible de la supuesta teluricidad e historicidad isleña: no se sabe dónde comienza un elemento y dónde termina el otro. El sumergimiento es la mejor manifestación del bloqueo marítimo, y por lo tanto, la circunstancia elemental de la cultura de la isla y del poeta (Quintero-Herencia, 2012: 81-82).

El mar es una frontera universalizable que, como en los mitos de los marineros, encierra todo tipo de monstruosidades. El agua -y sus misterio- por todas partes no es lo único que detiene a los prisioneros, también la imposibilidad de concretar la escapada; la desesperanza, la indiferencia dominan cualquiera de esas inquietudes. La voz lírica comenta que "Nadie puede salir: / el tiburón más diminuto rehusaría transportar un cuerpo intacto" (Piñera, 1969: 32). Como en el cuento "La carne", del mismo autor, el poema es repentinamente poblado por alusiones a la deglución en las que el individuo, en medio, se traga lo que puede, movido por su fijación a sobrevivir pese a todo: "Cada hombre comiendo fragmentos de la isla, / cada hombre devorando los frutos, las piedras y el excremento nutridor. / Cada hombre mordiendo el sitio dejado por su sombra, / cada hombre lanzando dentelladas en el vacío donde el sol se acostumbra..."(32-33).

La isla, según el juicio de la voz lírica, es un cáncer expuesto a todas horas ("madrugada, mediodía, crepúsculo y noche"), una herida que supura y no sana. Más adelante, el poema contrasta el estado isleño con la tibieza de la gente: "El rastro luminoso de un sueño mal parido, / un carnaval que empieza con el canto del gallo, / [...] / Es la hora terrible. / y todo el mundo toma su café (Piñera, 1969: 34). Como se ha insistido, la luz es intermitencia que permite la apreciación y la depreciación de la belleza, tan increíblemente intercambiable que podría sospecharse que es un artificio para inducir tribulaciones, lo que dificulta establecer lazos de confianza con nada que se pose sobre la isla.

Y ante la pregunta retórica y el reclamo que repite: “¿Qué puede el sol en un pueblo tan triste?” (Piñera, 1969: 34), el texto reverbera toda una serie de castigos y actos que desencadenan la luz sobre la piel de las víctimas. La voz poética se rebela con bríos que, poco a poco, se van aplacando mientras detalla las consecuencias minuciosamente: “¡Hay que tapar! ¡Hay que tapar! / Pero la claridad avanzada, invade / perversamente, oblicuamente, perpendicularmente, / la claridad es una enorme ventosa que chupa la sombra, / y las manos van lentamente hacia los ojos" (36). La luz, sin embargo, lo puede todo ante la insignificancia de los señalamientos pasionales del poeta. Las tentativas por tapar se reducen a proteger la mirada, pero esto no es suficiente, ya que bajo su fulgor:

Los secretos más inconfesables son dichos:

la claridad mueve las lenguas,

la claridad mueve los brazos, 
la claridad se precipita sobre un frutero de guayabas,

la claridad se precipita sobre los negros y los blancos,

la claridad se golpea a sí misma,

va de uno a otro lado convulsivamente,

empieza a estallar, a reventar, a rajarse,

la claridad empieza el alumbramiento más horroroso,

la claridad empieza a parir claridad.

Son las doce del día (36).

La luz se despliega en venganza de idéntica crueldad. Asimismo, con el verso siguiente: “Todo un pueblo puede morir de luz como morir de peste" (36), se hace hincapié en lo que previamente se había mencionado en relación con que "la luz, asociada al sol en tanto consecuencia directa suya, deviene objeto de escarnio piñeriano porque promueve una somnolencia general que anula el pensamiento y conduce a una especie de muerte simbólica: la enajenación del ser humano" (Hernández, 2013: 39-40). Hablando sobre luz, debe señalarse que es, en efecto, la voz poética la que asume la responsabilidad mesiánica de designar los males que circundan el lugar en cuestión. El escarnio piñeriano -por la iluminación de las cosa- deriva en la condición de ser testigo y hacerse testificante. En ese sentido, el desarrollador poemático, en su rol de observador y designador, exclama: “PPueblo mío, tan joven, no sabes ordenar! / ¡Pueblo mío, divinamente retórico, no sabes relatar! / Como la luz o la infancia aún no tienes un rostro" (Piñera, 1969: 37). Es evidente que el sujeto lírico se considera un iluminado -en un sentido pseudoascético-, conocedor de las claves para conseguir la armonía y, a su vez, el portavoz lo suficientemente apto como para atribuirse la misión de ser el responsable de contar la historia. En cierta forma, contrae esta asignación de autoridad, pues los modelos relatantes previos fracasaron en resolver las contradicciones del ser inteligible frente a la multitud crédula, sensible, domesticable. Por ende, el objetivo del poema:

[...] aspira a reivindicar la singularidad del poeta (el intelectual) en medio y por encima del entorno. La cubanía sería entonces una fatalidad geográfica, histórica y social que se da como algo ajeno al individuo y que él se esmera en rechazar en aras de la autoconservación. No obstante, fatalidad al fin, al sujeto le es imposible evadirla [...] "La isla en peso" testimonia ese tránsito desgarrador de una postura a otra, de lo extraño a lo entrañable, aunque sepamos que nunca gobierna una de las dos de modo definitorio (Hernández, 2013: 46-47).

\section{III.}

Bajo este condicionamiento fatalista, que opera tan exitosamente sobre los seres de los que se poetiza, el sujeto lírico termina por des-enrarecer ese universo caótico que existe más allá de su palabra. Entonces, ya en las postrimerías del texto, descubre que su labor es irrelevante, pues la existencia está garantizada con o sin su intervención. De esa manera, se incorpora en los ritos, se confunde con la masa -que en principio desdeñó por asilvestrada-, y declara que "[n]o queremos potencias celestiales sino presencias terrestres, que la tierra nos ampare, que nos ampare el deseo, 
felizmente no llevamos el cielo en la masa de la sangre, sólo sentimos su realidad física" (Piñera, 1969: 40). A fin de cuentas, es mayor "el peso de una isla en el amor de un pueblo" (40), que el proyecto salvador que se fraguaba en el inicio. Ante la observación minuciosa del mundo siendo mundo, del mundo girando en su eje, los tintes de rebeldía se han ido despintado, el afecto y el temor han venido a domesticar la mirada crítica del hablante como para que este pueda darse en paz al conformismo y a las trampas naturales del mar y la luz por doquier.

En "La isla en peso" la condición insular es la que, inicialmente, conduce a esta noción de encerramiento. Con todo, "[p]ara Piñera, la insularidad es fundante pero en un sentido negativo [...] Aquí es la construcción metafórica de la desgracia [...] es la isla de la tragedia y el lamento" (Isola, 2017: 71). Primero el mar como límite, luego la luz al servicio de la vigilancia y, por último, la gente operando desaforadamente bajo los estatutos de entrampamiento que solo el hablante lírico cree percibir. Los elementos carnavalescos colorean lo que la voz poética presume prisión. Por regla general, los habitantes del universo piñeriano destacan por enfrentarse privadamente a las crisis colosales que propician sus respectivos acabamientos. Cada uno de ellos, el que más como el que menos -incluido el hablante-, queda atrapado en una cárcel indefinida, que muta y se extiende. Y si después de todo, "un pueblo se hace y se deshace dejando los testimonios / [...] / sintiendo cómo el agua lo rodea por todas partes" (Piñera, 1969: 41-42), puede más el compromiso por definir al país, joven pero propio, que darse a la fatalidad de la cubanía y a la maldita circunstancia que representa un sitio.

\section{BIBLIOGRAFÍA}

Aguilar Santos, J. (2015). Orígenes y el discurso de la nación ausente. Islas, 57(180), 47-57.

Baquero, G. (1944). Tendencias de nuestra literatura. En: Anuario cultural de Cuba, 1943 (pp. 294-316). La Habana: Dirección General de Relaciones Culturales.

Cruikshank, S. A. (2016). Poetic Illiteracy and Cultural Insularity: The Crisis of Cultural Nationalism in Virgilio Piñera's La Isla en Peso. The Quiet Corner Interdisciplinary Journal, 1(2),16-26.

Hernández, M. de las N. (2013). La isla en peso de Virgilio Piñera: metamorfosis de un tigre queno existe. Revista Electrónica de Estudios Hispánicos, (13), 35-48.

Isola, L. (2017). Tres tristes tigres o el ensayo sobre la cubanidad en Ortiz, Sarduy y Piñera. Alea: Estudos Neolatinos, 19(1), 64-75.

Martin, R. (2009). Virgilio Piñera, contra y por la palabra. Revista Iberoamericana, 75(226), 33-53.

Molinero, R. (2012). Vida y destino de Virgilio Piñera: “otra broma colosal”. En Memorias del centenario de Virgilio Piñera: pequeñas maniobras (pp. 29-34). San Juan: Plaza Mayor. 
Piñera, V. (1969). La isla en peso. En La vida entera (pp. 25-42). Camagüey: UNEAC.

Quintero-Herencia, J. C. (2012). Del agua por todas partes: sensorio y política en Virgilio Piñera. En Memorias del centenario de Virgilio Piñera: pequeñas maniobras (pp. 79-83). San Juan: Plaza Mayor.

Vitier, C. (1948). Virgilio Piñera. En Diez poetas cubanos (1937-1947) (79-80). La Habana: Ediciones Orígenes.

Vitier, C. (1970). Lo cubano en la poesía. La Habana: Letras Cubanas.

Zoja, L. (2017). Paranoia: The Madness That Makes History. London and New York: Routledge, Taylor \& Francis Group. 